\title{
Safety and tolerability of adjunctive rosiglitazone treatment for children with uncomplicated malaria
}

\author{
Rosauro Varo ${ }^{1,2+}{ }^{,}$, Valerie M. Crowley ${ }^{3 \dagger}$, Antonio Sitoe ${ }^{2}$, Lola Madrid ${ }^{1,2}$, Lena Serghides ${ }^{4,5,6}$, Rubao Bila², \\ Helio Mucavele ${ }^{2}$, Alfredo Mayor ${ }^{1,2}$, Quique Bassat ${ }^{1,2,7^{*} \neq}$ and Kevin C. Kain ${ }^{3,8,9 \neq}$
}

\begin{abstract}
Background: Despite the widespread use and availability of rapidly acting anti-malarials, the fatality rate of severe malaria in sub-Saharan Africa remains high. Adjunctive therapies that target the host response to malaria infection may further decrease mortality over that of anti-malarial agents alone. Peroxisome proliferator-activated receptorgamma agonists (e.g. rosiglitazone) have been shown to act on several pathways implicated in the pathogenesis of severe malaria and may improve clinical outcome as an adjunctive intervention.

Methods: In this study, the safety and tolerability of adjunctive rosiglitazone in paediatric uncomplicated malaria infection was evaluated in Mozambique, as a prelude to its evaluation in a randomized controlled trial in paediatric severe malaria. The study was a prospective, randomized, double-blind, placebo-controlled, phase lla trial of rosiglitazone $(0.045 \mathrm{mg} / \mathrm{kg} / \mathrm{dose})$ twice daily for 4 days versus placebo as adjunctive treatment in addition to Mozambican standard of care (artemisinin combination therapy $\left(\right.$ Coartem $^{\circledR}$ ) in children with uncomplicated malaria. The primary outcomes were tolerability and safety, including clinical, haematological, biochemical, and electrocardiographic evaluations.
\end{abstract}

Results: Thirty children were enrolled: 20 were assigned to rosiglitazone and 10 to placebo. Rosiglitazone treatment did not induce hypoglycaemia nor significantly alter clinical, biochemical, haematological, or electrocardiographic parameters.

Conclusions: Adjunctive rosiglitazone was safe and well-tolerated in children with uncomplicated malaria, permitting the extension of its evaluation as adjunctive therapy for severe malaria.

The trial is registered with Clinicaltrials.gov, NCT02694874

\section{Background}

Malaria causes an estimated 212 million infections and 429,000 deaths annually [1]. Following the demonstration of the superiority of intravenous artesunate compared to quinine, artesunate has become the standard of

\footnotetext{
*Correspondence: quique.bassat@isglobal.org

${ }^{\dagger}$ Rosauro Varo and Valerie M. Crowley equally contributed to the work, and should share co-primary authorship

${ }^{\ddagger}$ Quique Bassat and Kevin C. Kain equally contributed to the work, and should share co-senior authorship

${ }^{2}$ Centro de Investigação em Saúde de Manhiça, Rua 12, Vila da Manhiça, 1929 Maputo, Mozambique

Full list of author information is available at the end of the article
}

care for severe malaria in both adults and children $[2,3]$. However, in spite of its improved efficacy over quinine, case fatality rates for severe malaria remain high, ranging from 8.5 to $30 \%[2,3]$. In addition, substantial post-severe malaria morbidity persists with long-term neurocognitive impairments, such as deficits in attention, memory, speech, and language reported in up to one-third of children surviving severe malaria [4-14]. Both parasite and host determinants contribute to the pathobiology of severe malaria. The host immune response plays a central role in the onset, severity and outcome of malaria infections, and this has accelerated the search for immunomodulatory adjunctive therapies that could improve 
clinical outcome. To date, several putative adjunctive strategies have been tested in severe malaria, however with disappointing results $[15,16]$.

Peroxisome proliferator-activated receptor-gamma (PPAR $\gamma$ ) is a member of the family of nuclear hormone receptors that function as ligand-activated transcription factors via their heterodimerization with another nuclear receptor, retinoic $X$ receptor (RXR) [17-19]. PPAR $\gamma$ agonists are promising candidates for adjunctive malaria treatment as they have been reported to have antiinflammatory, anti-oxidant, and neuroprotective properties [19-24]. The PPAR $\gamma$ agonist rosiglitazone is in the thiazolidinedione (TZD) class of drugs and is approved for the treatment of type II diabetes [25]. Rosiglitazone acts by increasing insulin sensitivity rather than increasing insulin levels, does not induce hypoglycaemia, and has an established safety profile in adults [25-29].

Rosiglitazone has been shown to enhance macrophage phagocytosis of Plasmodium falciparum parasitized erythrocytes, and to reduce parasite-induced pro-inflammatory cytokine secretion from monocytes and macrophages in vitro [30]. In a pre-clinical in vivo model of experimental cerebral malaria (ECM), rosiglitazone improved survival over artesunate alone, enhanced parasite clearance, reduced systemic inflammation and endothelial activation, prevented vascular leak, enhanced neuroprotective pathways, and protected mice from malaria-induced cognition and motor impairments [22, 31]. In light of these promising pre-clinical results, a randomized double-blind placebo controlled trial was conducted in young adults with uncomplicated malaria on the Thai-Cambodian border [32]. In this randomized trial, rosiglitazone was safe and well tolerated, and led to significantly improved parasite clearance times, lower levels of pro-inflammatory mediators, evidence of enhanced endothelial quiescence, and increased levels of the neuroprotective mediator brain-derived neurotropic factor (BDNF) [22, 32].

Together, these results support the hypothesis that adjunctive rosiglitazone may improve outcomes in patients with severe malaria. Since the majority of severe malaria and associated deaths occur in children under 5 years of age in sub-Saharan Africa, we conducted a phase IIa safety and tolerability trial in Mozambican children with uncomplicated malaria, as a prelude to undertaking a randomized trial in children with severe malaria.

\section{Methods}

\section{Study design and participants}

This was a prospective, parallel arm, unequally randomized, placebo-controlled, double-blind trial of rosiglitazone versus placebo, in 30 Mozambican children with uncomplicated malaria. All children received the Mozambican standard of care for uncomplicated malaria (Coartem ${ }^{\circledR}$ Dispersible; artemether-lumefantrine $20 \mathrm{mg} / 120 \mathrm{mg}$, Novartis) with dosage determined by body weight, twice daily as recommended by National guidelines [33]. An unequal randomization list (2:1, in favour of rosiglitazone) was generated using blocks of 3 , using the free online randomization software Sealed Envelope $^{\text {TM }}$ (https://www.sealedenvelope.com/). Randomization codes were placed inside individual sealed envelopes that were opened only by the nursing staff responsible for the administration of the drug. The remaining investigators were blind to the allocated intervention. All laboratory tests and statistical analyses were performed blinded to treatment group. Enrollment took place between February and March 2016.

\section{Ethical considerations}

This study was reviewed and approved by the Mozambican National Bioethics Committee (CNBS) (Ref. 230/CNBS/15), the pharmaceutical department of the Mozambican Ministry of Health (Ref. 374/380/DF2016), the Clinical Research Ethics Committee of the Hospital Clínic, Barcelona, Spain (Ref. HCB/2015/0981), and the University Health Network Research Ethics Committee, Toronto, Canada (UHN REB Number 15-9013-AE). All research was conducted according to the principles expressed in the Declaration of Helsinki. The trial was registered with ClinicalTrials.gov on 9 December 2015, NCT02694874. All participants and their parents/legal guardians were given detailed oral and written information about the trial, and children were recruited only after a written informed consent was signed by their parents/legal guardians. Verbal assent was obtained from children over the age of 8 .

\section{Study setting, inclusion and exclusion criteria}

The trial was conducted by the Centro de Investigação em Saúde de Manhiça (CISM) at the Manhiça District Hospital (MDH), in southern Mozambique. A detailed description of CISM may be found elsewhere [34]. In Mozambique, malaria transmission is perennial, with a seasonal peak from November to April [35]. Parents/ caregivers of children presenting to $\mathrm{MDH}$ were asked to participate in the trial and were screened for eligibility. Children, aged 1-12 years, were included in the study if they were positive for $P$. falciparum by microscopy, whereby a thick blood film confirmed malaria infection with parasitaemia $>2500$ parasites $/ \mu \mathrm{L}$. Children were excluded if they were known to have any known pre-existing illness (including neurological or neurodegenerative disorders, cardiac, renal or hepatic disease, diabetes, epilepsy, cerebral palsy), presented any reason for hospitalization, or if they had clinical or laboratory 
evidence of severe malaria (including severe anaemia, hypoglycaemia, acidosis, repeated seizures, prostration, impaired consciousness, respiratory distress, or ageadjusted tachypnea). Children receiving any therapy with potential anti-malarial activity (including cotrimoxazole), or treatment with a TZD were also excluded. Patients were approached after voluntarily presenting to $\mathrm{MDH}$ as part of routine care, and no financial incentives were provided.

\section{Intervention}

Rosiglitazone (Avandia ${ }^{\circledR}$, GlaxoSmithKline) and an identical looking placebo manufactured at the Hospital Clínic's pharmacology department in Barcelona, Spain, were packaged and labelled to ensure blinding of study staff and hospital personnel. Children received either rosiglitazone $(0.045 \mathrm{mg} / \mathrm{kg} /$ dose $)$ or placebo twice daily for 4 days [36]. This dose was based on the maximal dose used by the manufacturer in the pediatric evaluation of rosiglitazone in children 10-17 [36]. The study medication was administered at the hospital, within the Clinical Trials Unit, by authorized members of the study team only. The study intervention (rosiglitazone or placebo) was started together with the first dose of artemetherlumefantrine. The interventions were administered orally. If any patient vomited or otherwise expelled the medication within 5 min of administration, the patient would be retreated. Rosiglitazone and placebo tablets were crushed and administrated as a powder mixed in water.

\section{Treatment follow-up and laboratory procedures}

Following documentation of informed consent, participants had an initial targeted physical examination performed by the study physician. Anthropomorphic measures were calculated upon admission using the WHO AnthroPlus Software version 1.0.4 for children 0-19 years old [37]. A blood sample was taken at baseline and prior to the administration of the study intervention, for malaria diagnosis by microscopy, and haematological (haemoglobin, haematocrit, platelets, white cell full blood count) and biochemical (renal and liver function, glucose and lactate) evaluations. For a strict monitoring of glycaemia, finger-prick samples for glucose monitoring were obtained on admission, every $6 \mathrm{~h}$ for the first $48 \mathrm{~h}$, and then every $24 \mathrm{~h}$ until discharge, and again at the day 7 and day 14 follow-up visits. Hypoglycaemia was defined as blood glucose $<2.5 \mathrm{mmol} / \mathrm{L}$ (45 mg/dL) in an adequately-nourished child according to WHO definition [37]. Lactate was monitored on admission, every $12 \mathrm{~h}$ for the first $24 \mathrm{~h}$, and then every $24 \mathrm{~h}$ until discharge, and again at the day 7 and day 14 follow-up visits. Biochemistry, including aspartate aminotransferase (AST), alanine aminotransferase (ALT), urea, creatinine, lactate dehydrogenase (LDH), and indirect and direct bilirubin, were assessed in venous blood every $24 \mathrm{~h}$ from admission until discharge and once again on day 7 follow-up. Venous blood extraction for haematology was performed every $24 \mathrm{~h}$ from admission until discharge and again on day 7 and 14 follow-up. Finally, venous blood extraction for biomarker analysis was performed on admission, 12, 24, 36, 48, 60, 72, and $84 \mathrm{~h}$ after admission, and again at the day 7 and 14 follow-up visits. Electrocardiographic monitoring was performed using a portable 12 lead electrocardiogram (ECG) machine (Cardioline ECG100+; AB Medica Group SA) at screening (before administration of study interventions), on day 1 ( $24 \mathrm{~h}$ after admission and after the second dose of study intervention), and on day 4 (after the last dose of study intervention). An additional ECG was conducted on day 7, only if abnormalities were recorded on day 4 . The study clinicians reviewed all ECG tracings immediately after they were obtained, paying special attention to the QT segment length and potential prolongations from baseline. All children were kept at the health facility for the 4-day dosing period, despite being uncomplicated malaria cases. The mother/guardian was asked to return with the child for scheduled visits on day 7 and 14 post-treatment, or if any symptoms occurred. On each visit, a physical examination was performed by the study clinicians, vital signs were recorded, and body temperature measured.

\section{Outcomes}

The primary outcome was safety and tolerability over the first $84 \mathrm{~h}$ of hospital admission as determined by clinical, biochemical, haematological, and electrocardiographic observations according to specific pre-defined local reference ranges. Adverse events (AEs) and serious adverse events (SAEs) were recorded and monitored throughout the study.

\section{Statistical analyses}

Statistical analyses were performed with SPSS v.24 and Graph Pad Prism v.7. Differences between groups were assessed using the Fisher's exact test for categorical demographic values, and by $t$ test or Mann-Whitney $U$ test (two-tailed) for clinical laboratory data based on the distribution of the data. Glucose measures at each time point were compared using a Mann-Whitney $U$ test (two-tailed).

Mann-Whitney $U$ tests were used to compare the median changes from baseline for glucose, AST, ALT, haemoglobin and haematocrit between the two treatment arms. Mean haematocrit and haemoglobin values were compared using ANOVA. A p value $<0.05$ was considered as statistically significant. 


\section{Results}

The trial's flow diagram is shown in Fig. 1. Baseline characteristics were similar between the two treatment groups (Table 1). Clinical monitoring of vital signs, including respiratory rate, heart rate, blood pressure, and oxygen saturation levels did not differ between groups. All study patients, irrespective of randomization group, had an eventless clinical course. No adverse drug reactions were observed, and no patient vomited in either group. No patient enrolled in this study had a SAE or died.

Treatment with rosiglitazone did not induce hypoglycaemia, and all glucose were above the lower blood glucose threshold of $2.5 \mathrm{mmol} / \mathrm{L}$ (Fig. 2). Median changes in glucose levels between baseline and day 14 did not significantly differ between the placebo and rosiglitazone arms (1.2 vs. $0.3 \mathrm{mmol} / \mathrm{L}, \mathrm{p}=0.52)$. Only one isolated lactate value out of the normal range $(0-5 \mathrm{mmol} / \mathrm{L})$ was observed in a rosiglitazone-treated patient at $24 \mathrm{~h}$ post recruitment $(5.5 \mathrm{mmol} / \mathrm{L})$ that stabilized without any additional treatment.

Only two values of AST were out of range (0-100 U/L). These were observed at baseline in two children receiving placebo. They spontaneously normalized and were not associated with any clinical symptoms or signs. Median changes in AST levels between baseline and day 7 did not significantly differ between placebo and treatment arms (3.5 vs. $7 \mathrm{U}, \mathrm{p}=0.78$ ). Nor was there a significant difference in median changes in ALT between placebo and rosiglitazone treated participants $(3.5$ vs. $11 \mathrm{U}, \mathrm{p}=0.15$ ) between baseline and day 7 . For the remaining biochemical parameters, including urea, creatinine, LDH, direct or indirect bilirubin, no significant differences or trending abnormalities were observed.
Table 1 Patient characteristics on admission

\begin{tabular}{|c|c|c|c|}
\hline & Placebo, $\mathrm{N}=10$ & $\begin{array}{l}\text { Rosiglitazone, } \\
N=20\end{array}$ & $\mathbf{p}$ \\
\hline Female sex (\%) & $7(70 \%)$ & $11(55 \%)$ & 0.70 \\
\hline Age (years) ${ }^{a}$ & $8(4.6,9.1)$ & $6.9(4.7,9.8)$ & 0.92 \\
\hline Weight (kg) & $21.5[15.0,24.8]$ & $20.2[16.1,2.7]$ & 0.87 \\
\hline Height (cm) & $124.0[101.0,132.5]$ & $115.0[106.0,131.5]$ & 0.75 \\
\hline BMl/age & $-1.13[-1.40,-0.37]$ & $-0.15[-3.2,0.24]$ & 0.11 \\
\hline $\begin{array}{l}\text { Weight-for-age Z } \\
\text { score (WAZ) }\end{array}$ & $-1.1[-1.4,-0.73]$ & $-0.67[-1.5,0.81]$ & 0.34 \\
\hline Temperature $\left({ }^{\circ} \mathrm{C}\right)$ & $38.3[36.6,39.1]$ & $36.6[36.1,37.5]$ & 0.07 \\
\hline Heart rate (bpm) & $123.2(15.58)$ & $120.1(14.6)$ & 0.60 \\
\hline Glucose (mmol/L) & $7.2[5.3,8.3]$ & $5.9[5.1,7.3]$ & 0.40 \\
\hline Lactate (mmol/L) & $2.5[2.1,2.9]$ & $1.9[1.8,3.2]$ & 0.23 \\
\hline Haemoglobin (g/L) & $10.1(0.8)$ & $10.1(1.5)$ & 0.99 \\
\hline Haematocrit (\%) & $30.1(2.3)$ & $30.4(4.0)$ & 0.83 \\
\hline Leukocytes $\left(\times 10^{9} / \mathrm{L}\right)$ & $8.3(3.0)$ & $7.4(2.5)$ & 0.41 \\
\hline Platelets $\left(\times 10^{9} / \mathrm{L}\right)$ & $96.3(34.3)$ & $131.8(59.4)$ & 0.09 \\
\hline $\operatorname{AST}(U / L)$ & $53.8(41.7)$ & $36.4(10.5)$ & 0.08 \\
\hline $\operatorname{ALT}(\mathrm{U} / \mathrm{L})$ & $27.5[5.3,41.0]$ & $33[26,36.8]$ & 0.54 \\
\hline Urea (mg/dL) & $12.5[12.0,17.3]$ & $14.0[13.0,15.8]$ & 0.67 \\
\hline Creatinine $(\mu \mathrm{mol} / \mathrm{L})$ & $35.3[30.7,39.0]$ & $31.2[29.8,42.8]$ & 0.81 \\
\hline $\begin{array}{l}\text { Parasite density } \\
\text { (parasites/ } \mu \mathrm{L})\end{array}$ & $23,499\{4166,55,491\}$ & $24,622\{3346,91,869\}$ & 0.91 \\
\hline
\end{tabular}

Median [IQR] for non-normally distributed variables

Number (\%) for categorical variables

Parasite density is represented as geometric mean \{range\}

a Mean (SD) for normally distributed variables

Haematological adverse events were uncommon. Three children had a haemoglobin decrease $>2 \mathrm{~g} / \mathrm{dL}$ from their baseline values, and further two had a haemoglobin value

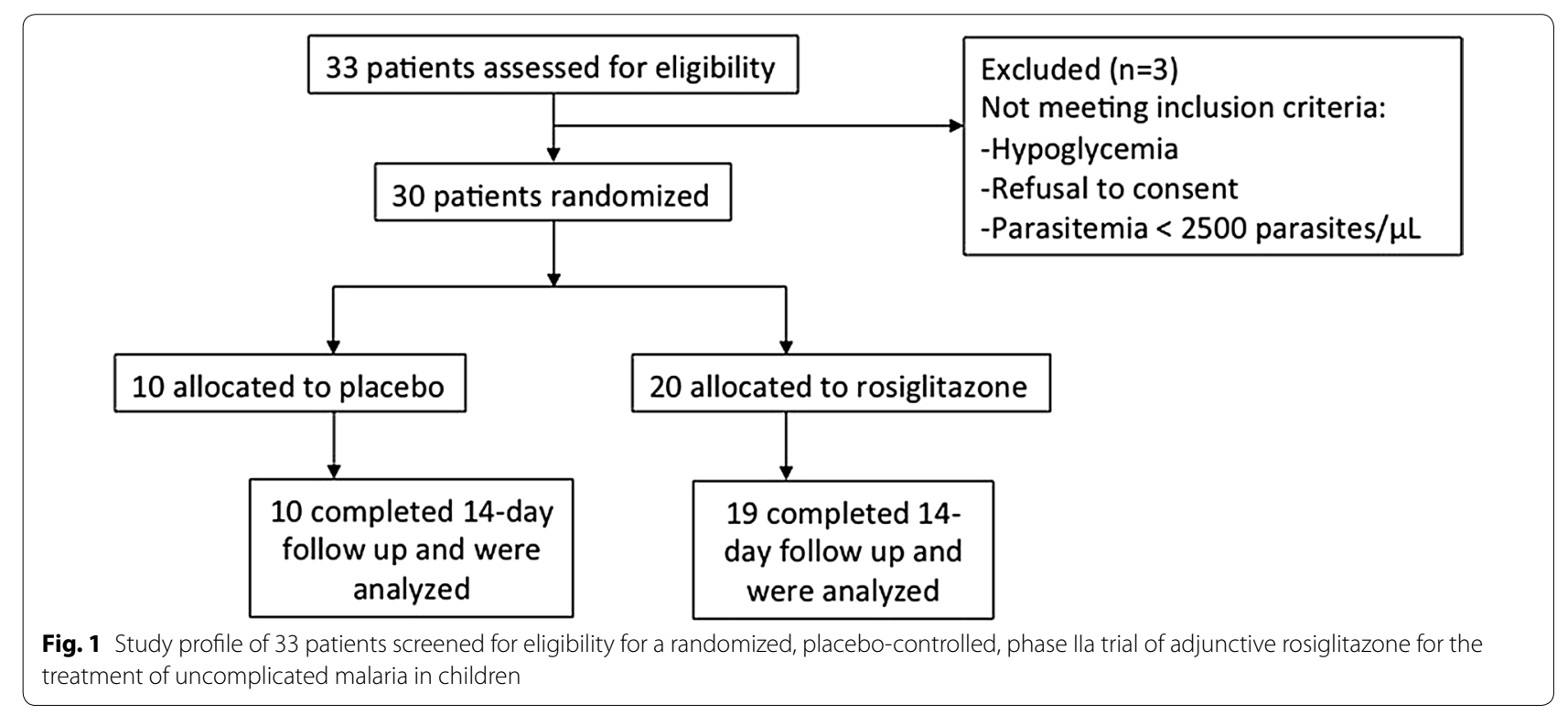




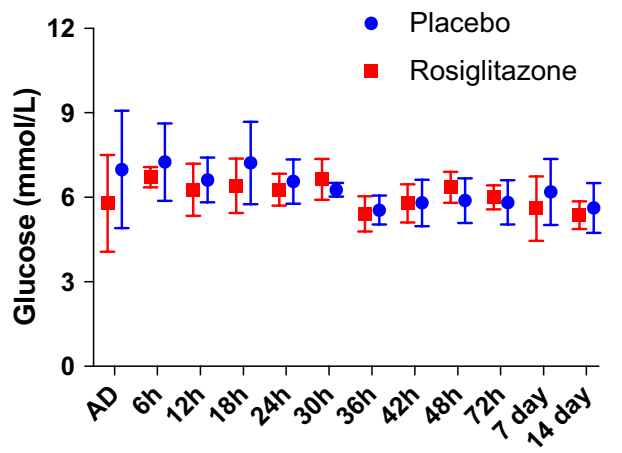

Fig. 2 Median glucose levels of study participants on admission (AD) and at each measured time point. Bars represent interquartile range

below the $7 \mathrm{~g} / \mathrm{dL}$ threshold; none were associated with clinical manifestations. Median changes in haemoglobin levels between baseline and day 14 did not significantly differ between the placebo and rosiglitazone arms $(0.4$ vs. $0.7 \mathrm{~g} / \mathrm{L}, \mathrm{p}=0.56)$. Median changes in haematocrit levels between baseline and day 14 did not significantly differ between the placebo and rosiglitazone arms $(0.4$ vs. $0.7 \mathrm{~g} / \mathrm{L}, \mathrm{p}=0.56)$. There was no significant difference between the treatment groups on haematocrit or haemoglobin levels $(\mathrm{p}=0.13$ and $\mathrm{p}=0.12$, respectively, Fig. 3). No differences in haematological parameters, including leukocytes, platelets or other components of the complete blood cell count, were observed between groups.

Table 2 summarizes all ECG abnormalities found during the study follow up. None of these events were associated with clinical findings or with the study intervention. No additional medication was administered to these patients. No patient had a QTc of more than $500 \mathrm{~ms}$ at any of the measured time points.

Mean parasite densities at baseline and throughout the study were similar between groups, (Fig. 4). Median time to parasite clearance was $33 \mathrm{~h}$ in both the rosiglitazone and placebo groups $(\mathrm{p}=0.88)$.

\section{Discussion}

In this study, the safety and tolerability of rosiglitazone as an adjunctive therapy for the treatment of uncomplicated malaria was investigated, as a first step before
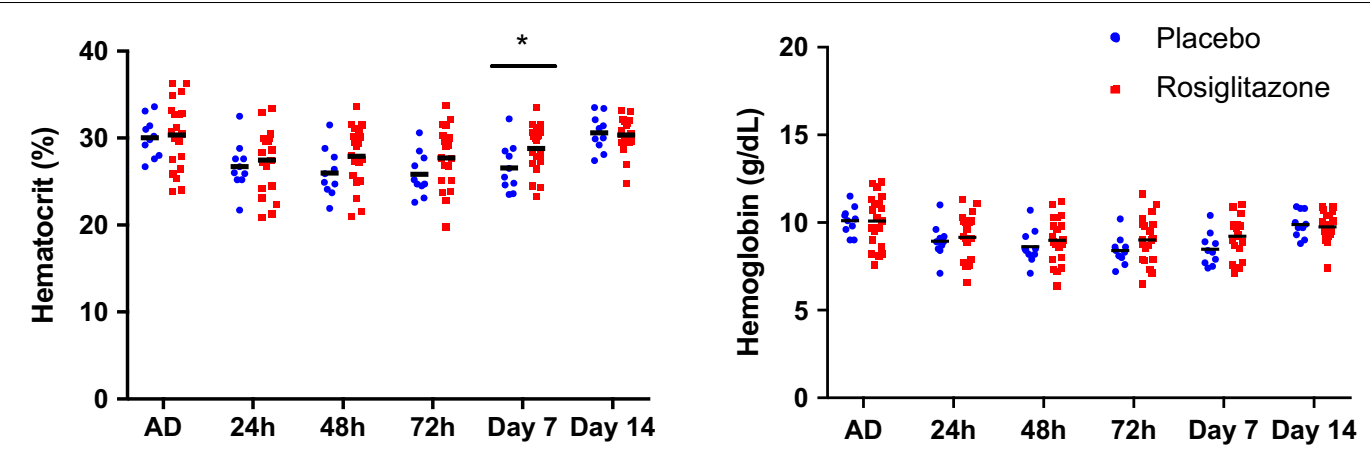

Fig. 3 Mean hematocrit and hemoglobin levels according to study group on admission (AD) and at each measured time point

Table 2 ECG abnormalities

\begin{tabular}{|c|c|c|c|c|}
\hline Patient & Treatment & QTc baseline (ms) & QTc maximum (ms) & ECG findings \\
\hline ROSI-002 & Rosiglitazone & 352 & 407 & Increase of QtcF >50 ms on day 4, NCS \\
\hline ROSI-007 & Rosiglitazone & 396 & 427 & Increase of QtcF >50 ms on day 2, NCS. Finished on day 4 \\
\hline ROSI-008 & Rosiglitazone & 356 & 424 & Increase of QtcF >50 ms on day 2, NCS. Continue on day 7, NCS \\
\hline ROSI-009 & Placebo & 342 & 425 & $\begin{array}{l}\text { Increase of QtcF }>50 \text { ms on day } 4 \text { with associated bradycardia, NCS } \\
\text { Increase of QtcF }>50 \text { ms on day 7, NCS and without bradycardia }\end{array}$ \\
\hline ROSI-010 & Placebo & 336 & 409 & Increase of QtcF >50 ms on day 4, NCS. Finished on day 7 \\
\hline ROSI-012 & Rosiglitazone & 323 & 404 & Increase of QtcF >50 ms on day 2, NCS. Finished on day 4 \\
\hline ROSI-014 & Placebo & 364 & 425 & $\begin{array}{l}\text { Left bundle branch block from screening, NCS } \\
\text { Increase of QtcF }>50 \text { ms on day 4, NCS. Finished on day } 14 \\
\text { Bradycardia on day 4, NCS }\end{array}$ \\
\hline ROSI-021 & Placebo & 361 & 414 & Increase of QtcF >50 ms on day 4, NCS. Finished on day 7 \\
\hline ROSI-022 & Placebo & 349 & 402 & Increase of QtcF $>50$ ms on day 4, NCS. Finished on day 7 \\
\hline
\end{tabular}

These abnormalities were not clinically significant (NCS). QT corrected for heart rate using Fridericia's method 


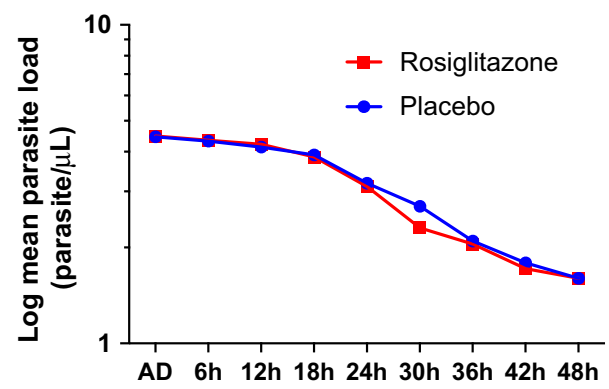

Fig. 4 Log mean parasite load in Mozambican children with uncomplicated malaria according to study group

evaluating its efficacy in the treatment of severe paediatric malaria and prevention of malaria-associated neurocognitive complications. Although rosiglitazone has a well-established safety profile, and millions of doses have been administered to adults with type II diabetes mellitus [38], this was the first time that the drug was used (off-label) as an adjunct to standard malaria treatment in African children. For this reason, and in concordance with recommendations issued by the CNBS, 30 children with uncomplicated malaria were carefully followed, and assessed for a variety of haematological, biochemical, clinical, and electrocardiographic safety variables, to ensure that the drug was not associated with adverse events. Although rosiglitazone was found to be safe and well-tolerated in children with uncomplicated malaria it cannot be assumed that a similar safety profile would be observed in children with severe malaria. Any future studies investigating the use of rosiglitazone for this purpose will be required to include additional safety evaluations.

Hypoglycaemia is a common and life-threatening complication of malaria [39], and drugs with negative effects on glycaemia levels would be problematic as adjuvant malaria therapies. Thus, particular attention was placed in assessing whether rosiglitazone would be associated with any glycaemia abnormalities in this population. Rosiglitazone acts by increasing insulin sensitivity rather than increasing insulin levels, and therefore, it is unlikely to induce hypoglycaemia. Although our sample size was small, it was reassuring that none of the malaria infected participants displayed glycaemia levels below $2.5 \mathrm{mmol} / \mathrm{L}$, and glycaemia levels were similar between the treatment and placebo groups.

A second important aspect of this trial was to assess potential adverse cardiac events. Initial case-control studies of long-term use in elderly high-risk diabetic patients reported a potential increase in acute cardiac events [28]; however these studies had methodological problems and recent reports from the USA Food and Drug Administration (FDA) have concluded that rosiglitazone is safe and was not associated with excess cardiovascular risk [28]. Importantly, as of June 2013, an FDA expert panel relaxed restrictions on this drug [29]. In agreement with these findings, no cardiac adverse events or increased risk over placebo were observed in a previous randomized trial in adults with uncomplicated malaria [32]. Similarly, and as anticipated for a paediatric non-diabetic patient population treated with a short course (4 days) of rosiglitazone, no cardiovascular adverse events were observed in this study. Additionally, some oral artemisinin-based combinations have been reported to induce prolongation of the electrocardiogram's QT interval, while malaria infection itself can increase the sympathetic tone of the heart, which manifests as a shortening of the QT interval in ECG traces [40]. Repeated ECG measurements detected only a few electrocardiographic abnormalities, none of which were deemed related to the investigational drug. The incidence and clinical significance of these electrocardiographic abnormalities were equally distributed between the placebo and rosiglitazone groups.

Rosiglitazone has been reported to decrease mean haemoglobin and haematocrit in a dose-related fashion in adults, particularly when it is taken on a daily basis [41]. This potential effect needed to be evaluated in the context of malaria, a disease often associated with decreases in haemoglobin levels. No major declines in haemoglobin or haematocrit were observed in either study arm, and no significant interaction between the study arm and sampling time were observed for either haemoglobin or haematocrit.

Rosiglitazone, malaria, and many anti-malarial drugs can be associated with increases in hepatic transaminases [41-44]. In this trial, transaminase levels were monitored in addition to direct and indirect bilirubin, and no patient receiving rosiglitazone had levels outside of the normal range.

This study was not powered to evaluate efficacy endpoints of rosiglitazone. As such, the outcomes of the uncomplicated malaria participants recruited to evaluate the safety and tolerability of the drug, may not be sufficiently informative of the potential that the drug has to impact the course of disease. Although increase parasite clearance times were previously observed in adult patients randomized to rosiglitazone in a previous randomized control trial these patients received atovaquone/proguanil [32]. Even with a study powered to study efficacy we may not see improved parasite clearance times due to the fast clearance of early rings by artemisinins. There is limited pharmacokinetic-pharmacodynamic data of rosiglitazone in children under the age of 10 . These data would have added more reassurance regarding the safety of rosiglitazone in children and is a 
limitation of the study. Further evaluation of rosiglitazone, when used as an adjunctive therapy in the context of severe malaria, will be required to explore its impact on pathways implicated in the pathogenesis and outcome of severe malaria.

\section{Conclusion}

This is the first report of rosiglitazone use in African children with an acute uncomplicated malaria infection. The safety and tolerability results, including no vomiting, no idiosyncratic drug reactions, and no serious adverse events support its continued evaluation as an adjuvant therapy in the treatment of severe paediatric malaria.

\begin{abstract}
Abbreviations
ACT: artemisinin-based combination therapy; AE: adverse events; ALT: alanine aminotransferase; Ang-2: angiopoeitin-2; AST: aspartate aminotransferase; BDNF: brain-derived neurotropic factor; CISM: Centro de Investigação em Saúde de Manhiça; CNBS: Mozambican National Bioethics Committee; ECM: experimental cerebral malaria; $\mathrm{LDH}$ : lactate dehydrogenase; $\mathrm{MDH}$ : Manhiça's District Hospital; ms: milliseconds; PPARY: peroxisome proliferator-activated receptor-gamma; RXR: retinoic X receptor; SAE: serious adverse event;TZD: thiazolidinedione.
\end{abstract}

\section{Authors' contributions}

KCK, LS and QB conceived of the study and KCK, QB, LS, RV and VMC contributed to study design. RV and AS acquired the data. KCK, QB, AM, RV, VMC and $\mathrm{LS}$ analysed and interpreted the data. KCK, QB, RV, VMC, LM, AM and LS drafted the manuscript. AM, LS, LM, QB, KK, VMC, RV, HM and RB critically revised the manuscript. All authors read and approved the final manuscript.

\section{Author details}

1 ISGlobal, Barcelona Institute for Global Health, Hospital Clínic, Universitat de Barcelona, Rosselló 132, 5th Floor, 08036 Barcelona, Spain. ${ }^{2}$ Centro de Investigação em Saúde de Manhiça, Rua 12, Vila da Manhiça, 1929 Maputo, Mozambique. ${ }^{3}$ S. A. Rotman Laboratories, Sandra Rotman Centre for Global Health, University Health Network-Toronto General Hospital, Toronto, Canada. ${ }^{4}$ Toronto General Research Institute (TGRI), University Health Network, Toronto, Canada. ${ }^{5}$ Women's College Research Institute, Women's College Hospital, Toronto, Canada. ${ }^{6}$ Department of Immunology and Institute of Medical Sciences University of Toronto, Toronto, Canada. ${ }^{7}$ ICREA, Pg. Lluís Companys 23, 08010 Barcelona, Spain. ${ }^{8}$ Department of Medicine, University of Toronto, Toronto, ON, Canada. ${ }^{9}$ Tropical Diseases Unit, Division of Infectious Diseases, Department of Medicine, UHN-Toronto General Hospital, Toronto, ON, Canada.

\section{Acknowledgements}

We thank all patients and their families for participation in this study. We thank the many nurses, field assistants and hospital staff that cared for the patients and collected study data specially Campos Mucasse, Humberto Mucasse and Ilidio Cherinda. This study was funded in part by the Canadian Institutes of Health Research (CIHR) Foundation Grant FDN-148439 (KCK) and a Canada Research Chair in Molecular Parasitology (KCK). Funders had no role in the design, conduct or decision to publish this study. The CISM receives financial support from the Spanish Agency for International Cooperation (AECI). ISGlobal is a member of the CERCA Programme, Generalitat de Catalunya. We thank our anonymous reviewers for their helpful comments.

\section{Competing interests}

The authors do not hold a patent for this indication of rosiglitazone. Quique Bassat had during the duration of the study a fellowship from the programme Miguel Servet of the ISCIII (Plan Nacional de I+D+I 2008-2011, Grant Number: CP11/00269). Lola Madrid had a fellowship from the programme Río Hortega of the ISCIII (CM13/00260) while the study was conducted.

\section{Publisher's Note}

Springer Nature remains neutral with regard to jurisdictional claims in published maps and institutional affiliations.

Received: 3 March 2017 Accepted: 12 May 2017

Published online: 23 May 2017

\section{References}

1. WHO. World malaria report 2016. Geneva: World Health Organization; 2016.

2. Dondorp A, Nosten F, Stepniewska K, Day N, White N, SEAQAMTS Group Artesunate versus quinine for treatment of severe falciparum malaria: a randomised trial. Lancet. 2005;366:717-25.

3. Dondorp AM, Fanello Cl, Hendriksen IC, Gomes E, Seni A, Chhaganlal KD, et al. Artesunate versus quinine in the treatment of severe falciparum malaria in African children (AQUAMAT): an open-label, randomised trial. Lancet. 2010;376:1647-57.

4. John CC, Bangirana P, Byarugaba J, Opoka RO, Idro R, Jurek AM, et al. Cerebral malaria in children is associated with long-term cognitive impairment. Pediatrics. 2008;122:e92-9.

5. Boivin MJ. Effects of early cerebral malaria on cognitive ability in Senegalese children. J Dev Behav Pediatr. 2002;23:353-64.

6. Boivin MJ, Bangirana P, Byarugaba J, Opoka RO, Idro R, Jurek AM, et al. Cognitive impairment after cerebral malaria in children: a prospective study. Pediatrics. 2007;119:e360-6.

7. Fernando SD, Rodrigo C, Rajapakse S. The 'hidden' burden of malaria: cognitive impairment following infection. Malar J. 2010;9:366.

8. Idro R, Kakooza-Mwesige A, Balyejjussa S, Mirembe G, Mugasha C, Tugumisirize J, et al. Severe neurological sequelae and behaviour problems after cerebral malaria in Ugandan children. BMC Res Notes. 2010:3:104.

9. Kihara M, Carter JA, Holding PA, Vargha-Khadem F, Scott RC, Idro R, et al. Impaired everyday memory associated with encephalopathy of severe malaria: the role of seizures and hippocampal damage. Malar J. 2009:8:273.

10. Birbeck GL, Molyneux ME, Kaplan PW, Seydel KB, Chimalizeni YF, Kawaza $\mathrm{K}$, et al. Blantyre Malaria Project Epilepsy Study (BMPES) of neurological outcomes in retinopathy-positive paediatric cerebral malaria survivors: a prospective cohort study. Lancet Neurol. 2010;9:1173-81.

11. Dugbartey AT, Dugbartey MT, Apedo MY. Delayed neuropsychiatric effects of malaria in Ghana. J Nerv Ment Dis. 1998;186:183-6.

12. Carter JA, Ross AJ, Neville BG, Obiero E, Katana K, Mung'ala-Odera V, et al. Developmental impairments following severe falciparum malaria in children. Trop Med Int Health. 2005;10:3-10.

13. Carter JA, Mung'ala-Odera V, Neville BG, Murira G, Mturi N, Musumba $C$, et al. Persistent neurocognitive impairments associated with severe falciparum malaria in Kenyan children. J Neurol Neurosurg Psychiatry. 2005;76:476-81.

14. Carter JA, Lees JA, Gona JK, Murira G, Rimba K, Neville BG, et al. Severe falciparum malaria and acquired childhood language disorder. Dev Med Child Neurol. 2006:48:51-7.

15. John CC, Kutamba E, Mugarura K, Opoka RO. Adjunctive therapy for cerebral malaria and other severe forms of Plasmodium falciparum malaria. Expert Rev Anti Infect Ther. 2010;8:997-1008.

16. Higgins SJ, Elphinstone RE, Kain KC. Adjunctive therapies for malaria. In: Encyclopedia of malaria. Media SSB ed. New York: Springer Science+Business Media; 2014.

17. Pascual G, Fong AL, Ogawa S, Gamliel A, Li AC, Perissi V, et al. A SUMOylation-dependent pathway mediates transrepression of inflammatory response genes by PPAR-gamma. Nature. 2005;437:759-63.

18. Giannini S, Serio M, Galli A. Pleiotropic effects of thiazolidinediones: taking a look beyond antidiabetic activity. J Endocrinol Invest. 2004;27:982-91.

19. Lehrke M, Lazar MA. The many faces of PPARgamma. Cell. 2005:123:993-9.

20. Kapadia R, Yi JH, Vemuganti R. Mechanisms of anti-inflammatory and neuroprotective actions of PPAR-gamma agonists. Front Biosci. 2008:13:1813-26 
21. Jin J, Albertz J, Guo Z, Peng Q, Rudow G, Troncoso JC, et al. Neuroprotective effects of PPAR- $\gamma$ agonist rosiglitazone in N171-82Q mouse model of Huntington's disease. J Neurochem. 2013;125:410-9.

22. Serghides L, McDonald CR, Lu Z, Friedel M, Cui C, Ho KT, et al. PPARY agonists improve survival and neurocognitive outcomes in experimental cerebral malaria and induce neuroprotective pathways in human malaria. PLoS Pathog. 2014;10:e1003980.

23. Cheng Y, Rodriguiz RM, Murthy SR, Senatorov V, Thouennon E, Cawley NX, et al. Neurotrophic factor-a1 prevents stress-induced depression through enhancement of neurogenesis and is activated by rosiglitazone. Mol Psychiatry. 2015;20:744-54.

24. Thouennon E, Cheng Y, Falahatian V, Cawley NX, Loh YP. Rosiglitazoneactivated PPARY induces neurotrophic factor-a1 transcription contributing to neuroprotection. J Neurochem. 2015;134:463-70.

25. Yki-Järvinen H. Thiazolidinediones. N Engl J Med. 2004;351:1106-18.

26. Salzman A, Patel J. Rosiglitazone is not associated with hepatotoxicity. Diabetes. 1999;48:A114-5.

27. Bale TL, Baram TZ, Brown AS, Goldstein JM, Insel TR, McCarthy MM, et al. Early life programming and neurodevelopmental disorders. Biol Psychiatry. 2010;68:314-9.

28. Nissen SE, Wolski K. Effect of rosiglitazone on the risk of myocardial infarction and death from cardiovascular causes. N Engl J Med. 2007;356:2457-71.

29. Hiatt WR, Kaul S, Smith RJ. The cardiovascular safety of diabetes drugs -insights from the rosiglitazone experience. N Engl J Med. 2013:369:1285-7.

30. Serghides L, Kain KC. Peroxisome proliferator-activated receptor gammaretinoid $X$ receptor agonists increase $C D 36$-dependent phagocytosis of Plasmodium falciparum-parasitized erythrocytes and decrease malariainduced TNF-alpha secretion by monocytes/macrophages. J Immunol. 2001;166:6742-8.

31. Serghides L, Patel SN, Ayi K, Lu Z, Gowda DC, Liles WC, et al. Rosiglitazone modulates the innate immune response to Plasmodium falciparum infection and improves outcome in experimental cerebral malaria. J Infect Dis. 2009;199:1536-45.

32. Boggild AK, Krudsood S, Patel SN, Serghides L, Tangpukdee N, Katz K, et al. Use of peroxisome proliferator-activated receptor gamma agonists as adjunctive treatment for Plasmodium falciparum malaria: a randomized, double-blind, placebo-controlled trial. Clin Infect Dis. 2009;49:841-9.

33. Mocambique. MdSRd. Programa Nacional de Controlo de Malaria: Normas de Tratamento da Malaria em Mocambique. Maputo 2011.

34. Sacoor C, Nhacolo A, Nhalungo D, Aponte JJ, Bassat Q, Augusto O, et al. Profile: Manhica Health Research Centre (Manhica HDSS). Int J Epidemiol. 2013;42:1309-18.

35. Bassat Q, Guinovart C, Sigauque B, Aide P, Sacarlal J, Nhampossa T, et al. Malaria in rural Mozambique. Part II: children admitted to hospital. Malar J. 2008;7:37.

36. Zawadzki JK. Clinical Review Pediatric Study Rosiglitazone (Avandia ${ }^{\circledR}$ ). GlaxoSmithKline 2004.

37. WHO. AnthroPlus Software version 1.0.4. Geneva: World Health Organization. 2007. http://www.who.int/growthref/tools/en/. Accessed 18 Nov 2016.

38. WHO. Pocket book for hospital care of children: guidelines for the management of common illness with limited resources. 2nd ed. Geneva: World Health Organization; 2013.

39. GlaxoSmithKline (GSK). Product Monograph, AVANDIA ${ }^{\circledR}$ rosiglitazone (as rosiglitazone maleate). Date of revision: 5th March 2012. http://ca.gsk. com/media/522034/avandia.pdf. Accessed 4 Dec 2016.

40. Madrid L, Lanaspa M, Maculuve SA, Bassat Q. Malaria-associated hypoglycaemia in children. Expert Rev Anti Infect Ther. 2015;13:267-77.

41. White NJ. Cardiotoxicity of antimalarial drugs. Lancet Infect Dis. 2007;7:549-58.

42. Jain A, Kaushik R, Kaushik RM. Malarial hepatopathy: clinical profile and association with other malarial complications. Acta Trop. 2016;159:95-105.

43. Bukirwa H, Unnikrishnan B, Kramer CV, Sinclair D, Nair S, Tharyan P. Artesunate plus pyronaridine for treating uncomplicated Plasmodium falciparum malaria. Cochrane Database Syst Rev. 2014;(3):CD006404. doi:10.1002/14651858.CD006404.pub2.

44. Croft AM, Whitehouse DP, Cook GC, Beer MD. Safety evaluation of the drugs available to prevent malaria. Expert Opin Drug Saf. 2002;1:19-27.

\section{Submit your next manuscript to BioMed Central and we will help you at every step:}

- We accept pre-submission inquiries

- Our selector tool helps you to find the most relevant journal

- We provide round the clock customer support

- Convenient online submission

- Thorough peer review

- Inclusion in PubMed and all major indexing services

- Maximum visibility for your research

Submit your manuscript at www.biomedcentral.com/submit
() Biomed Central 